\title{
MicroRNA regulation of the germinal center response
}

\author{
Dirk Baumjohann and K. Mark Ansel \\ Department of Microbiology \& Immunology, Sandler Asthma Basic Research Center, University of \\ California San Francisco, San Francisco, CA 94143, USA
}

\begin{abstract}
The generation of germinal centers (GCs) is a hallmark feature of the adaptive immune response, resulting in the production of high-affinity antibodies that neutralize pathogens and confer protection upon reinfection. The GC response requires interactions between different immune cell types, and the coordination of complex and dynamic gene expression networks within these cells. Here we provide deeper insights into how microRNAs, small endogenously expressed RNAs, regulate the cellular processes involved in the differentiation and function of $\mathrm{T}$ follicular helper cells and germinal center B cells, the two main players of the T cell-dependent humoral immune response.
\end{abstract}

\section{Introduction}

Germinal centers (GCs) are specialized structures that form within secondary lymphoid organs during $\mathrm{T}$ cell-dependent antibody responses [1]. They are the anatomical site of antigen-specific $\mathrm{B}$ cell proliferation and selection events that engender robust high-affinity antibody responses and $\mathrm{B}$ cell memory. Naïve $\mathrm{CD} 4^{+} \mathrm{T}$ cells are primed by dendritic cells in the $\mathrm{T}$ cell zone of secondary lymphoid organs and can differentiate into various effector $\mathrm{T}$ helper cells (Th1, Th2, Th17, etc.) or T follicular helper (Tfh) cells, which interact with B cells and support GC responses (Figure 1). The transcription factor Bcl6 is necessary and sufficient to induce the Tfh phenotype in activated CD4+ $\mathrm{T}$ cells [2-4]. Importantly, Bcl6 induction occurs independently of cognate interactions with B cells at these early stages of the immune response [5]. Induced upregulation of the chemokine receptor CXCR5 and downregulation of CCR7 by these early Tfh cells promotes their migration to the boundary of B cell follicles [6]. Naïve B cells encounter their antigen in the follicle and subsequently localize to these same boundary regions and interact with Tfh cells (Figure 1). This encounter initiates the extrafollicular antibody response in which the activated B cells differentiate into plasma blasts that produce the first wave of antibodies, generally of low affinity [7]. Only very few of the activated B cells, together with Tfh cells, reenter the follicle to establish germinal centers (Figure 1). GC B cells are the predominant antigenpresenting cell type in GCs, and their formation and maintenance requires CD40L provided

\footnotetext{
(C) 2014 Elsevier Ltd. All rights reserved.

Publisher's Disclaimer: This is a PDF file of an unedited manuscript that has been accepted for publication. As a service to our customers we are providing this early version of the manuscript. The manuscript will undergo copyediting, typesetting, and review of the resulting proof before it is published in its final citable form. Please note that during the production process errors may be discovered which could affect the content, and all legal disclaimers that apply to the journal pertain.
} 
by Tfh cells. Thus, Tfh and GC B cells are maintained through reciprocal interactions within GCs $[8,9]$. In these multicellular structures somatic hypermutation and affinity maturation lead to the generation of memory B cells and long-lived plasma cells that produce highaffinity antibodies [1]. Most vaccines aim at inducing this second wave of potent antibodies, which provides protection upon re-infection with the same pathogen that elicited the primary response.

Dysregulation of the GC response is a key feature of several autoimmune diseases [10, 11] and GC B cells are the cell of origin for several common types of B cell lymphoma [12]. Harnessing the immunological power of these volatile structures involves orchestrated interactions among several different cell types, and it is not surprising that gene expression within these cells is tightly regulated as well. MicroRNAs are small endogenously expressed RNAs that have emerged as important constituents of gene regulatory networks in the immune system $[13,14]$. Here, we discuss our current understanding of how miRNAs contribute to gene regulation and decision-making in the GC response, especially with regard to the two main players, Tfh cells and B cells.

\section{MicroRNA-mediated regulation of T follicular helper cells}

Tfh cells are the primary $\mathrm{T}$ cell subset that provides help to B cells [15]. They have a distinct miRNA expression profile $[4,16]$ and requirements for miRNA function that differ from those of other effector Th cell subsets [13]. Global miRNA expression by $\mathrm{CD} 4^{+} \mathrm{T}$ cells is absolutely required for Tfh cell development, as adoptively transferred DiGeorge syndrome critical region gene 8 (Dgcr8)-deficient T cells, which lack mature miRNAs, failed to generate $\mathrm{CXCR} 5^{+} \mathrm{Bcl}^{+} \mathrm{Tfh}$ cells upon immunization with a protein antigen [17]. In addition, activated miRNA-deficient $\mathrm{CD} 4^{+} \mathrm{T}$ cells failed to downregulate $\mathrm{CCR} 7$ and were unable to localize to the T-B zone border and interfollicular regions where wildtype $\mathrm{T}$ cells interact with activated B cells [17]. Importantly, this defect was not only attributed to the reduced proliferative capacity of miRNA-deficient $\mathrm{CD} 4^{+} \mathrm{T}$ cells [13], but also to an intrinsic defect to generate Tfh cells [17]. The observed complete block in Tfh cell differentiation by $\mathrm{CD}^{+}{ }^{+} \mathrm{T}$ cells that lack all miRNAs is very striking, since miRNA-deficient $\mathrm{CD} 4^{+} \mathrm{T}$ cells can still differentiate very efficiently into other Th cell subsets [13].

So far, studies of the particular miRNAs that regulate Tfh cell differentiation and function have been focused mostly on the miR-17 92 cluster, which consists of six miRNAs that comprise four different miRNA families. Overexpression of miR-17 92 in T helper cells causes hyperproliferation and the production of autoantibodies [18]. On the molecular level, miR-17 92 was shown to repress the expression of the anti-apoptotic protein Bim and the tumor suppressor PTEN [18]. Early studies indicated that miR-17 92 may inhibit Tfh cell responses by directly targeting CXCR5 expression, and that miR-17 92 may itself be regulated by Bcl6 [4]. However, more recent data clarified that miR-17 92 in fact promotes Tfh cell differentiation through repression of several target genes, including Pten [17, 19]. miR-17 92 also regulates Tfh cell development in part by targeting Phlpp2an AKT phosphatase involved in ICOS signaling, which is important for the co-localization of Tfh and B cells [19]. Members of the miR-17 92 family and Phlpp2 are rapidly induced upon T cell stimulation and follow similar expression kinetics [19]. Inhibition of Phlpp2 by 
miR-17 92 miRNAs might thus be important for adjusting the appropriate strength of ICOS-mediated signaling required for Tfh cell differentiation [19]. Combined deletion of miR-17 92 and its two related miRNA clusters, miR-106a 363 and miR-106b 25, further amplified the defects in Tfh cell differentiation, although miR-17 92 alone was shown to be the main contributor to the observed phenotype [19]. Follicular regulatory T (Tfr) cells share characteristics of thymus-derived Treg cells and Tfh cells and are believed to regulate the germinal center response, although the precise mechanisms remain elusive [20]. Tfr cells seem to be particularly dependent on miR-17 92, as Tfr numbers in mice that either lacked or overexpressed miR-17 92 specifically in T cells correlated with miR-17 92 dose [17].

Tfh cell differentiation is critically supported by multiple inhibitory pathways, including the transcriptional repressor Bcl6 and miRNAs (Figure 1). This indicates that repression of alternative differentiation pathways may be very important for the establishment and maintenance of Tfh cell identity. This idea is further supported by recent data obtained from experiments with conditional miR-17 92-deficient mice in a viral infection model [17]. In wildtype mice, lymphocytic choriomeningitis virus (LCMV) infection primarily generates Th1 and Tfh cells. However, miR-17 92-deficient Tfh cells from LCMV-infected mice upregulated a whole array of genes that are normally associated with Th17 and Th22 cells, including Ccr6, Il22and Rora [17]. All six miRNAs of the miR-17 92 cluster directly target the Rora 3' UTR, and restoring Rora expression to its normal lower level in miR-17 92deficient Tfh cells significantly rescued the inappropriate expression of Ccr6 and Il22. Similarly, miR-10a inhibits the conversion of Foxp $3^{+}$Treg cells into Tfh cells under lymphopenic conditions, in part by targeting Bcl6 and its co-repressor Ncor2 [21]. Together, these data demonstrate that miRNAs can enforce $\mathrm{T}$ helper cell identities by restraining alternative transcriptional programs (Figure 1).

\section{MicroRNA-mediated regulation of the germinal center B cell response}

MicroRNAs play essential roles in several aspects of B cell development and immune function, including the GC response [22]. This was revealed through several studies that used Cre recombinase transgenes to conditionally inactivate the miRNA biogenesis enzyme Dicer at different stages of B cell development in mice. Deletion very early in the B cell lineage with Mb1-Cre blocks B cell development at the pro- to pre-B cell transition [23]. Deletion at later stages of B cell development (using CD19-Cre) showed that miRNAs also specifically promote the generation of follicular B cells, while transitional and marginal zone B cell numbers were increased [24]. Interestingly, Dicer deletion at this stage also resulted in a skewed $\mathrm{B}$ cell receptor $(\mathrm{BCR})$ repertoire and high titers of autoreactive antibodies [24]. More recent studies using mice that express Cre recombinase only in activated $B$ cells under the control of the activation-induced cytidine deaminase (AID) promoter provided further insights into miRNA regulation of $\mathrm{B}$ cell immune function. Global miRNA-deficiency limited to AID-expressing cells strongly impaired GC responses and memory B cell and plasma cell generation [25].

Various human and murine B cell subsets have been profiled by microarrays and sequencing, resulting in a comprehensive assessment of miRNA expression in these cells [16, 26-28]. The specific functional roles of some of these miRNAs have been elucidated. 
miR-155 has been the focus of perhaps the most intensive research on miRNA function in any mammalian system. It is highly expressed in GC B cells, and miR-155-deficient and miR-155-overexpressing mice revealed important roles for this miRNA in several aspects of the GC response (Figure 1), including GC size and number, antibody production, classswitch $_{\mathrm{DB} 2}$ affinity maturation, and cytokine production by Th cells [29, 30]. miR-155 negatively regulates the generation of class-switched $\mathrm{IgG}^{+}$plasma cells in part through inhibition of the transcription factor Pu.1 [31]. Deletion of miR-155 in lupus-prone Fas ${ }^{l p r}$ mice alleviated the systemic autoimmune response by decreasing the levels of autoantibodies in these mice [32]. AID is another important direct target of miR-155 [33, 34]. Since miR-155 promotes the GC B cell response, it is interesting that at the same time it inhibits AID, which is required for somatic hypermutation and also for class-switch recombination. Bcl6 inhibits the expression of several miRNAs, including miR-155, suggesting that coordinated spatiotemporal regulation of Bcl6 and miR-155 expression within the GC may be important for the generation of high-affinity B cells [35].

Several other miRNAs have been implicated to be important regulators of the GC B cell response (Figure 1). For example, miR-185 controls B cell activation through inhibition of Bruton tyrosine kinase, leading to dampened BCR signaling [24]. Like miR-155, miR-181b also impairs class-switch recombination in activated B DB3 cells by targeting AID [36]. miR-150 is highly expressed in naïve B cells and limits the magnitude of the GC response [37]. In contrast, miR-125b overexpression promotes GC B cell differentiation by inhibiting genes that drive plasma cell differentiation, including Blimp-1 and IRF4 [38]. The catalogue of miRNAs involved in GC responses will undoubtedly grow with further investigation and development of tools for assessing miRNA functions in immunity.

\section{MicroRNAs in the development of GC-derived malignancies}

The high frequency of genetic rearrangements in GC B cells makes them a common cell of origin for B cell lymphomas [12]. Dysregulated miRNA expression is a common feature of GC B cell-derived malignancies, and some of these miRNAs appear to be important oncogenes or tumor suppressors [22, 39]. Although miR-155 dampens genomic instability through the repression of AID, overexpression causes B cell leukemogenesis [40]. Indeed, miR-155 is the functional RNA encoded within the avian bic proto-oncogene, and it is highly expressed in Hodgin's lymphoma, diffuse large B cell lymphoma (DLBCL), and other hematologic malignancies [41]. In addition to promoting GC B cell differentiation, miR-125b overexpression induces B cell malignancies in transgenic mice [42].

The proto-oncogene miR-17 92 has been shown to drive the development of B cell lymphomas in a c-Myc-induced tumor model system by repressing genes that are important for apoptosis [43]. Dicer-deficient B cells exhibit an increase in the expression of miR-17 92 cluster target genes, including the proapoptotic protein Bim [23]. Generation and analysis of conditional miR-17 92-deficient mice contributed greatly to our understanding of the role of this miRNA cluster to normal B cell development in vivo [44]. The related miR-106a 363 and miR-106b 25 clusters share some, but not all of miR-17 92's regulatory properties [44]. Subsequent analyses revealed that miR-19 family miRNAs, which are represented once in the miR-106a 363 cluster and twice in miR-17 92, 
are particularly important for lymphomagenesis, in part through inhibition of the tumor suppressor gene Pten [45, 46]. Transgenic miR-17 92 overexpression in B cells efficiently induces lymphomas [47, 48], and c-Myc-induced tumor formation absolutely requires two functional copies of miR-17 92 [48]. Biochemical analysis of miRNA targeting by photoactivatable-ribonucleoside-enhanced crosslinking and immunoprecipitation (PARCLIP) showed that miR-17 92 directly targets multiple negative regulators of lymphomagenesis, including genes involved in the PI3K and NF-kB pathways [48]. Thus, miR-17 92 and other miRNAs participate in a complex gene regulatory network, and imbalance in this network can promote tumor development.

Follicular dendritic cells (FDCs) are localized in the light zone of the GC. They capture immune complexes through their abundant expression of complement and $\mathrm{Fc}$ receptors and present antigen to GC B cells. This contributes to positive selection of GC B cells and affinity maturation in a T cell-dependent manner. Although data is limited on how miRNAs might regulate FDCs themselves, FDCs have been implicated in regulating the balance between BLIMP-1 and BCL6 expression in B cells in a cell-to-cell contact-dependent manner through miR-9, let-7, and miR-30 [49]. In a different study, adhesion to FDCs was shown to induce miR-181a expression in B cell lymphoma cell lines, which correlated with decreased apoptosis and reduced expression of the pro-apoptotic miR-181a target gene Bim [50].

\section{Conclusion}

Over the past several years, miRNAs have emerged as important regulators of immune cells. This is reflected in the absolute requirement for miRNAs for the generation of Tfh and GC B cells. Of note, Tfh and GC B cell differentiation pathways are regulated by common transcriptional repressors: While Bcl6 drives the differentiation of both Tfh and GC B cells, Blimp-1 antagonizes Bcl6 function by promoting effector $\mathrm{T}$ cell and plasma cell differentiation, respectively [51, 52] (Figure 1). It is tempting to speculate that complex miRNA networks may also cooperate in both Tfh and GC B cells to modulate related gene expression programs that contribute to the cell fate decisions in the GC. For example, miR-155, one of the most heavily studied miRNAs in lymphocytes, has both positive and negative effects on the GC B cell response. This highlights the complexity of miRNAs in regulating cell functions. Interestingly, miR-155 may also regulate Tfh function through cMaf, a bona fide miR-155 target that is important for IL-4 production by Th2 cells [29].

Future studies will further unravel the roles of particular miRNAs and the genetic networks they affect. Given that individual miRNAs can target hundreds of genes, detailed assessment of these global networks will provide unprecedented views on the function of miRNAs in these cells. Continued progress will also yield novel insights into the regulatory pathways that govern immune cell function, and holds promise for the development of therapies that target miRNAs or their target genes in autoimmune diseases and malignancies that derive from dysregulated GC responses. 


\section{Acknowledgments}

This work was supported by the NIH (HL109102, HL107202) and a Scholar Award from The Leukemia \& Lymphoma Society (K.M.A.), and by the National Multiple Sclerosis Society and the UCSF Program for Breakthrough Biomedical Research (D.B.).

\section{References and recommended reading}

Papers of particular interest, published within the period of review, have been highlighted as:

- of special interest:

•• of outstanding interest:

1. Victora GD, Nussenzweig MC. Germinal centers. Annu Rev Immunol. 2012; 30:429-457. [PubMed: 22224772]

2. Johnston RJ, Poholek AC, DiToro D, Yusuf I, Eto D, Barnett B, Dent AL, Craft J, Crotty S. Bcl6 and Blimp-1 are reciprocal and antagonistic regulators of $\mathrm{T}$ follicular helper cell differentiation. Science. 2009; 325:1006-1010. [PubMed: 19608860]

3. Nurieva RI, Chung Y, Martinez GJ, Yang XO, Tanaka S, Matskevitch TD, Wang YH, Dong C. Bcl6 mediates the development of T follicular helper cells. Science. 2009; 325:1001-1005. [PubMed: 19628815]

4. Yu D, Rao S, Tsai LM, Lee SK, He Y, Sutcliffe EL, Srivastava M, Linterman M, Zheng L, Simpson $\mathrm{N}$, et al. The transcriptional repressor Bcl-6 directs T follicular helper cell lineage commitment. Immunity. 2009; 31:457-468. [PubMed: 19631565]

5. Ma CS, Deenick EK, Batten M, Tangye SG. The origins, function, and regulation of T follicular helper cells. J Exp Med. 2012; 209:1241-1253. [PubMed: 22753927]

6. Vinuesa CG, Cyster JG. How T cells earn the follicular rite of passage. Immunity. 2011; 35:671680. [PubMed: 22118524]

7. MacLennan IC, Toellner KM, Cunningham AF, Serre K, Sze DM, Zuniga E, Cook MC, Vinuesa CG. Extrafollicular antibody responses. Immunol Rev. 2003; 194:8-18. [PubMed: 12846803]

8. Baumjohann D, Preite S, Reboldi A, Ronchi F, Ansel KM, Lanzavecchia A, Sallusto F. Persistent antigen and germinal center B cells sustain $\mathrm{T}$ follicular helper cell responses and phenotype. Immunity. 2013; 38:596-605. [PubMed: 23499493]

9. Deenick EK, Chan A, Ma CS, Gatto D, Schwartzberg PL, Brink R, Tangye SG. Follicular helper T cell differentiation requires continuous antigen presentation that is independent of unique $\mathrm{B}$ cell signaling. Immunity. 2010; 33:241-253. [PubMed: 20691615]

10. Vinuesa CG, Sanz I, Cook MC. Dysregulation of germinal centres in autoimmune disease. Nat Rev Immunol. 2009; 9:845-857. [PubMed: 19935804]

11. Craft JE. Follicular helper T cells in immunity and systemic autoimmunity. Nat Rev Rheumatol. 2012; 8:337-347. [PubMed: 22549246]

12. Klein U, Dalla-Favera R. Germinal centres: role in B-cell physiology and malignancy. Nat Rev Immunol. 2008; 8:22-33. [PubMed: 18097447]

13. Baumjohann D, Ansel KM. MicroRNA-mediated regulation of T helper cell differentiation and plasticity. Nat Rev Immunol. 2013; 13:666-678. [PubMed: 23907446] This study demonstrates that global miRNA expression by $\mathrm{T}$ cells is required for Tfh cell differentiation and that miR-17 92 represses subset-inappropriate gene expression by Tfh cells.

14. Ansel KM. RNA regulation of the immune system. Immunol Rev. 2013; 253:5-11. [PubMed: 23550634]

15. Crotty S. Follicular Helper CD4 T Cells (T(FH)). Annu Rev Immunol. 2011; 29:621-663. [PubMed: 21314428]

16. Kuchen S, Resch W, Yamane A, Kuo N, Li Z, Chakraborty T, Wei L, Laurence A, Yasuda T, Peng $\mathrm{S}$, et al. Regulation of microRNA expression and abundance during lymphopoiesis. Immunity. 2010; 32:828-839. [PubMed: 20605486] 
17. Baumjohann D, Kageyama R, Clingan JM, Morar MM, Patel S, de Kouchkovsky D, Bannard O, Bluestone JA, Matloubian M, Ansel KM, et al. The microRNA cluster miR-17 approximately 92 promotes TFH cell differentiation and represses subset-inappropriate gene expression. Nat Immunol. 2013; 14:840-848. [PubMed: 23812098]

18. Xiao C, Srinivasan L, Calado DP, Patterson HC, Zhang B, Wang J, Henderson JM, Kutok JL, Rajewsky K. Lymphoproliferative disease and autoimmunity in mice with increased miR-17-92 expression in lymphocytes. Nat Immunol. 2008; 9:405-414. [PubMed: 18327259] Demonstration that overexpression of miR-17 92 in T cells leads to hypergammaglobulinemia and autoantibody production

19. Kang SG, Liu WH, Lu P, Jin HY, Lim HW, Shepherd J, Fremgen D, Verdin E, Oldstone MB, Qi $\mathrm{H}$, et al. MicroRNAs of the miR-17 approximately 92 family are critical regulators of TFH differentiation. Nat Immunol. 2013; 14:849-857. [PubMed: 23812097] This study demonstrates that miR-17 92 promotes Tfh cell differentiation in part by modulating the PI3K and ICOS signaling pathways

20. Ramiscal RR, Vinuesa CG. T-cell subsets in the germinal center. Immunol Rev. 2013; 252:146155. [PubMed: 23405902]

21. Takahashi H, Kanno T, Nakayamada S, Hirahara K, Sciume G, Muljo SA, Kuchen S, Casellas R, Wei L, Kanno Y, et al. TGF-beta and retinoic acid induce the microRNA miR-10a, which targets Bcl-6 and constrains the plasticity of helper T cells. Nat Immunol. 2012; 13:587-595. [PubMed: 22544395]

22. de Yebenes VG, Bartolome-Izquierdo N, Ramiro AR. Regulation of B-cell development and function by microRNAs. Immunol Rev. 2013; 253:25-39. [PubMed: 23550636]

23. Koralov SB, Muljo SA, Galler GR, Krek A, Chakraborty T, Kanellopoulou C, Jensen K, Cobb BS, Merkenschlager M, Rajewsky N, et al. Dicer ablation affects antibody diversity and cell survival in the B lymphocyte lineage. Cell. 2008; 132:860-874. [PubMed: 18329371]

24. Belver L, de Yebenes VG, Ramiro AR. MicroRNAs prevent the generation of autoreactive antibodies. Immunity. 2010; 33:713-722. [PubMed: 21093320]

25. Xu S, Guo K, Zeng Q, Huo J, Lam KP. The RNase III enzyme Dicer is essential for germinal center B-cell formation. Blood. 2012; 119:767-776. [PubMed: 22117047]

26. Landgraf P, Rusu M, Sheridan R, Sewer A, Iovino N, Aravin A, Pfeffer S, Rice A, Kamphorst AO, Landthaler M, et al. A mammalian microRNA expression atlas based on small RNA library sequencing. Cell. 2007; 129:1401-1414. [PubMed: 17604727]

27. Basso K, Sumazin P, Morozov P, Schneider C, Maute RL, Kitagawa Y, Mandelbaum J, Haddad J $\mathrm{Jr}$, Chen CZ, Califano A, et al. Identification of the human mature B cell miRNome. Immunity. 2009; 30:744-752. [PubMed: 19446474]

28. Malumbres R, Sarosiek KA, Cubedo E, Ruiz JW, Jiang X, Gascoyne RD, Tibshirani R, Lossos IS. Differentiation stage-specific expression of microRNAs in B lymphocytes and diffuse large B-cell lymphomas. Blood. 2009; 113:3754-3764. [PubMed: 19047678]

29. Rodriguez A, Vigorito E, Clare S, Warren MV, Couttet P, Soond DR, van Dongen S, Grocock RJ, Das PP, Miska EA, et al. Requirement of bic/microRNA-155 for normal immune function. Science. 2007; 316:608-611. [PubMed: 17463290] First description of a single miRNA regulating several aspects of the $\mathrm{GC}$ response

30. Thai TH, Calado DP, Casola S, Ansel KM, Xiao C, Xue Y, Murphy A, Frendewey D, Valenzuela D, Kutok JL, et al. Regulation of the germinal center response by microRNA-155. Science. 2007; 316:604-608. [PubMed: 17463289] First description of a single miRNA regulating several aspects of the GC response

31. Vigorito E, Perks KL, Abreu-Goodger C, Bunting S, Xiang Z, Kohlhaas S, Das PP, Miska EA, Rodriguez A, Bradley A, et al. microRNA-155 regulates the generation of immunoglobulin classswitched plasma cells. Immunity. 2007; 27:847-859. [PubMed: 18055230]

32. Thai TH, Patterson HC, Pham DH, Kis-Toth K, Kaminski DA, Tsokos GC. Deletion of microRNA-155 reduces autoantibody responses and alleviates lupus-like disease in the Faslpr mouse. Proc Natl Acad Sci U S A. 2013; 110:20194-20199. [PubMed: 24282294]

33. Dorsett Y, McBride KM, Jankovic M, Gazumyan A, Thai TH, Robbiani DF, Di Virgilio M, Reina San-Martin B, Heidkamp G, Schwickert TA, et al. MicroRNA-155 suppresses activation-induced 
cytidine deaminase-mediated Myc-Igh translocation. Immunity. 2008; 28:630-638. [PubMed: 18455451] These studies demonstrated that miR-155 is a negative regulator of activation-induced cytidine deaminase (AID).

34. Teng G, Hakimpour P, Landgraf P, Rice A, Tuschl T, Casellas R, Papavasiliou FN. MicroRNA-155 is a negative regulator of activation-induced cytidine deaminase. Immunity. 2008; 28:621-629. [PubMed: 18450484] These studies demonstrated that miR-155 is a negative regulator of activation-induced cytidine deaminase (AID).

35. Basso K, Schneider C, Shen Q, Holmes AB, Setty M, Leslie C, Dalla-Favera R. BCL6 positively regulates AID and germinal center gene expression via repression of miR-155. J Exp Med. 2012; 209:2455-2465. [PubMed: 23166356]

36. de Yebenes VG, Belver L, Pisano DG, Gonzalez S, Villasante A, Croce C, He L, Ramiro AR. miR-181b negatively regulates activation-induced cytidine deaminase in B cells. J Exp Med. 2008; 205:2199-2206. [PubMed: 18762567]

37. Xiao C, Calado DP, Galler G, Thai TH, Patterson HC, Wang J, Rajewsky N, Bender TP, Rajewsky K. MiR-150 controls B cell differentiation by targeting the transcription factor c-Myb. Cell. 2007; 131:146-159. [PubMed: 17923094]

38. Gururajan M, Haga CL, Das S, Leu CM, Hodson D, Josson S, Turner M, Cooper MD. MicroRNA $125 \mathrm{~b}$ inhibition of B cell differentiation in germinal centers. Int Immunol. 2010; 22:583-592. [PubMed: 20497960]

39. Di Leva G, Garofalo M, Croce CM. MicroRNAs in Cancer. Annu Rev Pathol. 2013

40. Costinean S, Zanesi N, Pekarsky Y, Tili E, Volinia S, Heerema N, Croce CM. Pre-B cell proliferation and lymphoblastic leukemia/high-grade lymphoma in E(mu)-miR155 transgenic mice. Proc Natl Acad Sci U S A. 2006; 103:7024-7029. [PubMed: 16641092]

41. Vigorito E, Kohlhaas S, Lu D, Leyland R. miR-155: an ancient regulator of the immune system. Immunol Rev. 2013; 253:146-157. [PubMed: 23550644]

42. Enomoto Y, Kitaura J, Hatakeyama K, Watanuki J, Akasaka T, Kato N, Shimanuki M, Nishimura $\mathrm{K}$, Takahashi M, Taniwaki M, et al. Emu/miR-125b transgenic mice develop lethal B-cell malignancies. Leukemia. 2011; 25:1849-1856. [PubMed: 21738213]

43. He L, Thomson JM, Hemann MT, Hernando-Monge E, Mu D, Goodson S, Powers S, CordonCardo C, Lowe SW, Hannon GJ, et al. A microRNA polycistron as a potential human oncogene. Nature. 2005; 435:828-833. [PubMed: 15944707] Characterization of miR-17 92 as a human oncogene.

44. Ventura A, Young AG, Winslow MM, Lintault L, Meissner A, Erkeland SJ, Newman J, Bronson RT, Crowley D, Stone JR, et al. Targeted deletion reveals essential and overlapping functions of the miR-17 through 92 family of miRNA clusters. Cell. 2008; 132:875-886. [PubMed: 18329372]

45. Mu P, Han YC, Betel D, Yao E, Squatrito M, Ogrodowski P, de Stanchina E, D'Andrea A, Sander C, Ventura A. Genetic dissection of the miR-17 92 cluster of microRNAs in Myc-induced B-cell lymphomas. Genes Dev. 2009; 23:2806-2811. [PubMed: 20008931]

46. Olive V, Bennett MJ, Walker JC, Ma C, Jiang I, Cordon-Cardo C, Li QJ, Lowe SW, Hannon GJ, He L. miR-19 is a key oncogenic component of mir-17-92. Genes Dev. 2009; 23:2839-2849. [PubMed: 20008935]

47. Sandhu SK, Fassan M, Volinia S, Lovat F, Balatti V, Pekarsky Y, Croce CM. B-cell malignancies in microRNA Emu-miR-17 92 transgenic mice. Proc Natl Acad Sci U S A. 2013; 110:1820818213. [PubMed: 24145403]

48. Jin HY, Oda H, Lai M, Skalsky RL, Bethel K, Shepherd J, Kang SG, Liu WH, Sabouri-Ghomi M, Cullen BR, et al. MicroRNA-17 92 plays a causative role in lymphomagenesis by coordinating multiple oncogenic pathways. EMBO J. 2013; 32:2377-2391. [PubMed: 23921550]

49. Lin J, Lwin T, Zhao JJ, Tam W, Choi YS, Moscinski LC, Dalton WS, Sotomayor EM, Wright KL, Tao J. Follicular dendritic cell-induced microRNA-mediated upregulation of PRDM1 and downregulation of BCL-6 in non-Hodgkin's B-cell lymphomas. Leukemia. 2011; 25:145-152. [PubMed: 20966935]

50. Lwin T, Lin J, Choi YS, Zhang X, Moscinski LC, Wright KL, Sotomayor EM, Dalton WS, Tao J. Follicular dendritic cell-dependent drug resistance of non-Hodgkin lymphoma involves cell 
adhesion-mediated Bim down-regulation through induction of microRNA-181a. Blood. 2010; 116:5228-5236. [PubMed: 20841506]

51. Crotty S, Johnston RJ, Schoenberger SP. Effectors and memories: Bcl-6 and Blimp-1 in T and B lymphocyte differentiation. Nat Immunol. 2010; 11:114-120. [PubMed: 20084069]

52. Nutt SL, Tarlinton DM. Germinal center B and follicular helper T cells: siblings, cousins or just good friends? Nat Immunol. 2011; 12:472-477. [PubMed: 21739669] 


\section{Highlights}

- Germinal centers (GCs) are hallmark structures of humoral immunity

- MicroRNAs (miRNAs) are important regulators of T follicular helper (Tfh) cell differentiation

- miRNAs regulate several aspects of the GC B cell response

- miRNA dysregulation in T and B cells contributes to the development of autoimmunity and cancer 


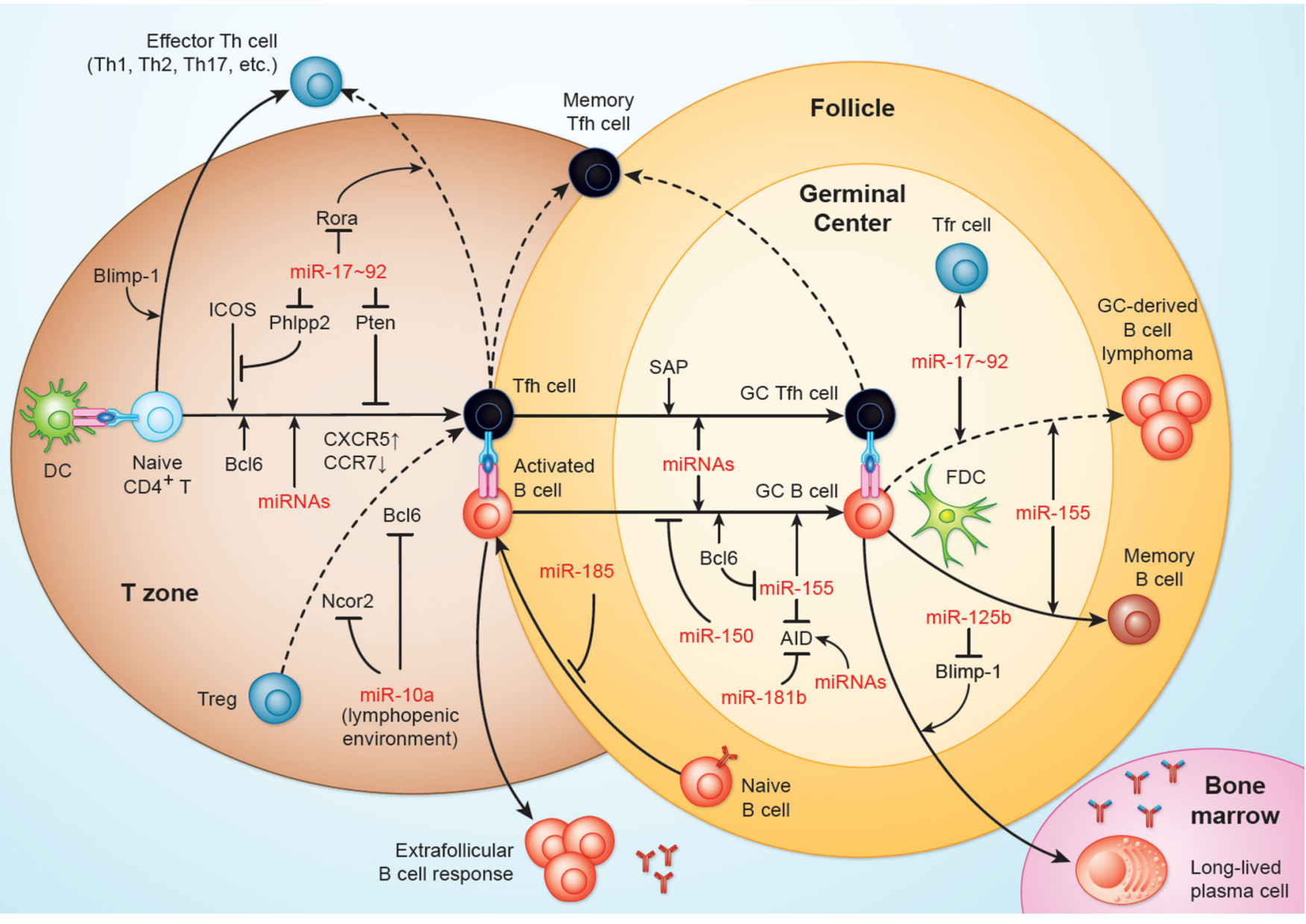

Figure 1. MicroRNA regulation of the germinal center response

MicroRNAs (miRNAs) regulate distinct aspects of the germinal center (GC) response. Upon priming by antigen-presenting dendritic cells (DCs) in the T cell area of secondary lymphoid organs, naïve $\mathrm{CD}^{+} \mathrm{T}$ cells differentiate into effector $\mathrm{T}$ helper $(\mathrm{Th})$ cells that migrate into the periphery where they mediate their effector functions. T follicular helper (Tfh) cells are also generated during priming by DCs. These early Tfh cells upregulate the transcriptional repressor Bcl6 and the costimulatory molecule ICOS. Subsequent upregulation of the chemokine receptor CXCR5 and downregulation of CCR7 enables these cells to localize to the T-B zone border and interfollicular regions where they interact with activated B cells in a cognate fashion. The induction of the Tfh cell gene expression program is dependent on miRNA expression by $\mathrm{T}$ cells. miR-17 92 promotes Tfh cell differentiation by repressing Pten and Phlpp2the latter being an important regulator downstream in the ICOS signaling pathway. In addition, miR-17 92 prevents co-expression of effector Th cell genes that are normally not expressed by Tfh cells through repression of Rora. The generation of $\mathrm{T}$ follicular regulatory (Tfr) cells residing in the GC is particularly sensitive to miR-17 92 dosage. miR-10a prevents the conversion of Foxp $3^{+}$Treg cells into Tfh cells under lymphopenic conditions. The Tfh gene expression program may serve as an intermediate state in effector Th cell subset differentiation, and Tfh cells may also persist as memory cells. While most activated B cells enter the extrafollicular pathway, some clones, together 
with Tfh cells, reenter the follicle in a process that requires Bc16 and SLAM-associated protein (SAP) expression by B and T cells, respectively, to establish GCs. In these structures, B cells undergo somatic hypermutation, affinity maturation, and class switch recombination to generate memory B cells and long-lived plasma cells, which produce highaffinity antibodies. miRNA expression by B cells is required for robust GC B cell responses. miR-155 regulates several aspects of the GC reaction, exerting a positive net effect.

Nevertheless, miR-155 has also been shown to repress AID, a gene that is required for somatic hypermutation and class-switch recombination. miR-155 itself is regulated by Bcl6. miR-185 inhibits B cell activation, and overexpression of miR-150 or miR-181b inhibits GC $B$ cell responses. Plasma cell differentiation is inhibited by miR-125b through repression of Blimp-1 and other targets. Overexpression of miR-155 or miR-17 92 promotes GC B cell lymphomagenesis. Follicular dendritic cells (FDCs) might regulate miRNA expression in GC B cells through cell adhesion, a process that has also been correlated with lymphomagenesis. 